\title{
Effects of different annuloplasty ring types on mitral leaflet tenting area during acute myocardial ischemia
}

\author{
Wolfgang Bothe, MD, ${ }^{\mathrm{a}}$ John-Peder Escobar Kvitting, MD, PhD, ${ }^{a}$ Elizabeth H. Stephens, PhD, ${ }^{\mathrm{b}}$ \\ Julia C. Swanson, MD, ${ }^{a}$ David H. Liang, MD, PhD, ${ }^{c}$ Neil B. Ingels, Jr, PhD, ${ }^{\mathrm{a}, \mathrm{d}}$ and D. Craig Miller, $\mathrm{MD}^{\mathrm{a}}$
}

Objective: The study objective was to quantify the effects of different annuloplasty rings on mitral leaflet septallateral tenting areas during acute myocardial ischemia.

\begin{abstract}
Methods: Radiopaque markers were implanted along the central septal-lateral meridian of the mitral valve in 30 sheep: 1 each to the septal and lateral aspects of the mitral annulus and 4 and 2 along the anterior and posterior mitral leaflets, respectively. Ten true-sized Carpentier-Edwards Physio, Edwards IMR ETLogix, and GeoForm annuloplasty rings (Edwards Lifesciences, Irvine, Calif) were inserted in a releasable fashion. Marker coordinates were obtained using biplane videofluoroscopy with ring inserted at baseline (RING_BL) and after 90 seconds of left circumflex artery occlusion (RING_ISCH). After ring release, another dataset was acquired before (No_Ring_BL) and after left circumflex artery occlusion (No_Ring_ISCH). Anterior and posterior mitral leaflet tenting areas were computed at mid-systole from sums of marker triangles with the midpoint between the annular markers being the vertex for all triangles.
\end{abstract}

Results: Compared with No_Ring_BL, mitral regurgitation grades and all tenting areas significantly increased with No_Ring_ISCH. Compared with No_Ring_ISCH, (1) all rings significantly prevented mitral regurgitation and reduced all tenting areas; (2) Edwards IMR ETLogix and GeoForm rings reduced posterior mitral leaflet area, but not anterior mitral leaflet tenting area, to a significantly greater extent than the Carpentier-Edwards Physio ring; and (3) Edwards IMR ETLogix and GeoForm rings affected tenting areas similarly.

Conclusions: In response to acute left ventricular ischemia, disease-specific functional/ischemic mitral regurgitation rings (Edwards IMR ETLogix, GeoForm) more effectively reduced posterior mitral leaflet area, but not anterior mitral leaflet tenting area, compared with true-sized physiologic rings (Carpentier-Edwards Physio). Despite its radical 3-dimensional shape and greater amount of mitral annular septal-lateral downsizing, the GeoForm ring did not reduce tenting areas more than the Edwards IMR ETLogix ring, suggesting that further reduction in tenting areas in patients with FMR/IMR may not be effectively achieved on an annular level. (J Thorac Cardiovasc Surg 2011;141:345-53)

Functional mitral regurgitation (FMR) and ischemic mitral regurgitation (IMR) are associated with left ventricular (LV) dilatation and papillary muscle displacement, ${ }^{1}$ which

\footnotetext{
From the Department of Cardiothoracic Surgery, ${ }^{\text {a }}$ Stanford University School of Medicine, Stanford, Calif; Department of Bioengineering, ${ }^{\mathrm{b}}$ Rice University, Houston, Tex; Division of Cardiovascular Medicine, ${ }^{\mathrm{c}}$ Stanford University School of Medicine, Stanford, Calif; and Laboratory of Cardiovascular Physiology and Biophysics, ${ }^{\mathrm{d}}$ Research Institute of the Palo Alto Medical Foundation, Palo Alto, Calif. Read at the 90th Annual Meeting of The American Association for Thoracic Surgery, Toronto, Ontario, Canada, May 1-5, 2010.

Supported by Grants HL-29589 and HL-67025 from the National Heart, Lung, and Blood Institute.

Disclosures: Dr Kvitting was funded by the US-Norway Fulbright Foundation, Swedish Heart-Lung Foundation, and Swedish Society for Medical Research. Dr Swanson was funded by Western States Affiliate American Heart Association Postdoctoral Fellowship. Dr Miller is a consultant for Medtronic Heart Valve Division, Inc, and St Jude Medical, and is a non-compensated member of the Edwards PARTNER US Pivotal Trial Executive Committee.

Received for publication April 22, 2010; revisions received Sept 4, 2010; accepted for publication Oct 16, 2010.

Address for reprints: D. Craig Miller, MD, Department of Cardiothoracic Surgery, Falk Cardiovascular Research Center, Stanford University School of Medicine, Stanford, CA 94305-5247 (E-mail: dcm@stanford.edu). 0022-5223/\$0.00

Published by Elsevier Inc. on behalf of The American Association for Thoracic Surgery

doi:10.1016/j.jtcvs.2010.10.015
}

leads, via annular dilation and chordal tethering, to complex 3-dimensional (3-D) alterations of the mitral valve geometry. While the central anterior leaflet belly displaces toward the apex (leaflet tenting), ${ }^{2-7}$ the edges of the anterior and posterior leaflets may displace apically, prolapse, or both. ${ }^{8}$

Various parameters are available to describe and quantify changes in leaflet geometry during FMR/IMR. ${ }^{3-7,9,10}$ One of the most common parameters to quantify the degree of FMR/IMR includes the assessment of the mitral leaflet tenting area, which describes the area between mitral annulus and both leaflets in a central, longitudinal, septal-lateral (S-L), mitral-annular cross-section during systole. The amount of tenting area strongly correlates with the severity of FMR/IMR ${ }^{6}$ and may be a predictive factor of recurrent mitral regurgitation (MR) in patients with FMR/IMR who are undergoing mitral valve repair. ${ }^{11}$

Although the results of surgical valve repair for FMR/ IMR have significantly improved, with rigid, undersizedring annuloplasty having become the current procedure of choice, ${ }^{3}$ outcomes continue to be suboptimal with current 


$$
\begin{aligned}
& \text { Abbreviations and Acronyms } \\
& \begin{aligned}
\text { AML } & =\text { anterior mitral leaflet } \\
\text { C-C } & =\text { commissure-commissure } \\
\text { ETL } & =\text { IMR ETLogix } \\
\text { FMR } & =\text { functional mitral regurgitation } \\
\text { GEO } & =\text { GeoForm } \\
\text { IMR } & =\text { ischemic mitral regurgitation } \\
\text { LCx } & \text { left circumflex artery } \\
\text { LV } & =\text { left ventricular } \\
\text { MR } & =\text { mitral regurgitation } \\
\text { Physio } & =\text { PHYSIO } \\
\text { PML } & =\text { posterior mitral leaflet } \\
\text { S-L } & =\text { septal-lateral } \\
\text { 3-D } & =3 \text {-dimensional }
\end{aligned}
\end{aligned}
$$

\section{MATERIALS AND METHODS Surgical Preparation}

Thirty-six adult, Dorsett-hybrid, male sheep $(49 \pm 4 \mathrm{~kg})$ were premedicated with ketamine $(25 \mathrm{mg} / \mathrm{kg}$ intramuscularly), anesthetized with sodium thiopental $(6.8 \mathrm{mg} / \mathrm{kg}$ intravenously), intubated, and mechanically ventilated with inhalational isoflurane $(1.0 \%-2.5 \%)$. All animals received humane care in compliance with the Principles of Laboratory Animal Care formulated by the National Society of Medical Research and the Guide for Care and Use of Laboratory Animals prepared by the National Academy of Sciences and published by the National Institutes of Health (DHEW NIHG publication 85-23, revised 1985). This study was approved by the Stanford Medical Center Laboratory Research Animal Review committee and conducted according to Stanford University policy.

Via a left thoracotomy, 13 radiopaque markers were implanted to silhouette the LV at the cross-section points of 4 equally spaced longitudinal and 3 equatorial meridians as described previously. ${ }^{18}$ With the use of cardiopulmonary bypass and cardioplegic arrest, 8 radiopaque markers were implanted as follows: Two markers were sewn to the S-L aspect (numbers 22 and 18, Figure 1,A), and 2 markers were sewn to the anterior and posterior mitral annular commissures, respectively. Four and two markers were sutured along the S-L meridian of the anterior mitral leaflets (AMLs) (A1-A4, Figure 1, A) and posterior mitral leaflets (PMLs) (P1 and P2, Figure $1, A$ ), respectively (single tantalum loops, $0.6 \mathrm{~mm}$ internal diameter, $1.1 \mathrm{~mm}$ outer diameter, $3.2 \mathrm{mg}$ each). To allow each animal to serve as its own control, a Carpentier-Edwards PHYSIO, an Edwards ETL, or an Edwards GEO annuloplasty ring (Edwards Lifesciences) was implanted in a releasable fashion as previously described. ${ }^{19}$

In brief, the mid parts of 8 double-armed polyester sutures were placed evenly spaced through the annuloplasty ring before the operation using a French eye needle, and the resulting loops were locked with polypropylene sutures (locking sutures). In addition, 2 drawstring sutures were attached to the ring. During the operation, the ends of the 8 polyester sutures were sewn equidistantly in a perpendicular direction from the ventricular to the atrial side through the mitral annulus. The annuloplasty ring was secured to the mitral annulus by tying these sutures. The locking sutures and drawstrings were exteriorized, and the left atrium was closed. Animals were randomly assigned to receive the Cosgrove-Edwards (Edwards Lifesciences), St Jude Medical RSAR (St Paul, Minn), PHYSIO, or GEO ring. Because this article focuses on the effects of IMR-specific annuloplasty rings, data on the Cosgrove and RSAR rings are not reported. After the implantation of these 4 ring types, the ETL was added. Consequently, animals receiving this ring type were not randomized. All annuloplasty rings were true-sized by assessing the height and entire AML area. Because all animals had similarly sized leaflets, all received size 28 rings. The left circumflex artery (LCx) was then encircled with a vessel loop immediately distal to the first obtuse marginal branch. The sheep, while intubated and anesthetized, were then transferred with the chest open to the experimental catheterization laboratory.

\section{Data Acquisition}

Some 6 of the 36 animals could not be used for data acquisition because of complications related to the surgical procedure and induction of ischemia. Videofluoroscopic images (60 frames/sec) of all radiopaque markers were acquired using biplane videofluoroscopy (Philips Medical Systems, North America, Pleasanton, Calif). Figure 1, $C$ shows the experimental protocol schematically. First, images were acquired with the ring inserted under baseline (BL) conditions (PHYSIO:Ring_BL, ETL:Ring_BL, GEO:Ring_BL). Acute LV ischemia was then induced by tightening the LCx loop for 90 seconds, and another dataset under ischemic conditions (ISCH) was obtained (PHYSIO:Ring_ISCH, ETL:Ring_ISCH, GEO:Ring_ISCH). The locking sutures were then withdrawn, and the ring was lifted away from the mitral annulus into the left atrium using the drawstrings. After hemodynamic values returned to baseline, a third data acquisition was performed and images were acquired under baseline conditions 

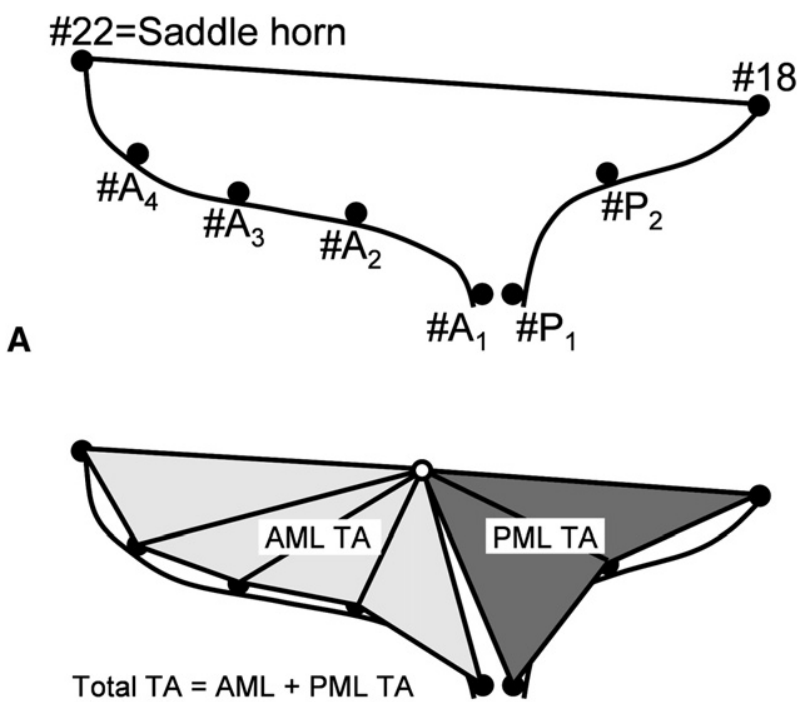

B

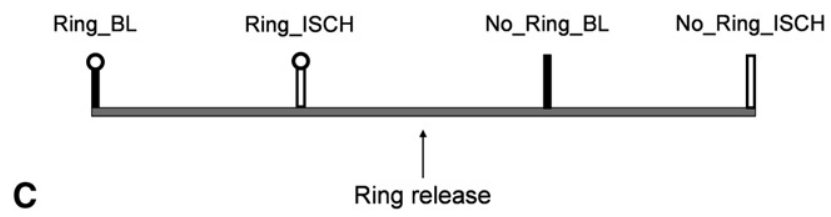

FIGURE 1. A, Marker array used to delineate the $\mathrm{S}$-L aspects of the mitral annulus (22 and 18), AML (A1-4), and PML (P1 and 2). B, Calculation of AML and PML tenting areas. C, Experimental protocol timeline (see "Materials and Methods" for details). $A M L$, Anterior mitral leaflet; $B L$, baseline; $I S C H$, ischemia; $P M L$, posterior mitral leaflet; $T A$, tenting area.

with the ring released (PHYSIO:No_Ring_BL, ETL:No_Ring_BL, GEO:No_Ring_BL). As described previously, these baseline data without ring implanted are comparable to baseline data from studies in which no ischemia was induced and no ring was implanted. ${ }^{19}$ After the acquisition of baseline data with no ring implanted, 90 seconds of $\mathrm{LCx}$ ischemia was induced (PHYSIO:No_Ring_ISCH, ETL:No_Ring_ISCH, GEO:No_Ring_ISCH). To determine whether 90 seconds of LCx occlusion would be appropriate to assess differences among ring types, LV geometry and papillary muscle displacement vectors during this ischemia period were analyzed and found to be similar to historic studies from our laboratory in which longer periods of acute ischemia were induced.

Marker coordinates from 3 consecutive sinus rhythm beats from each of the biplane views were then digitized and merged to yield the time-resolved 3-D coordinates of each marker centroid in each frame using semiautomated image processing and digitization software. ${ }^{20,21}$ Electrocardiogram and analog LV pressure were recorded in real-time on the video images. The amount of MR after each data acquisition run was independently graded by an expert echocardiographer (D.H.L.) on the basis of color Doppler regurgitant jet extent and width ${ }^{22}$ and categorized as none $(0)$, mild $(+1)$, moderate $(+2)$, moderate-to-severe $(+3)$, or severe $(+4)$.

\section{Data Analysis}

For each beat, end diastole was defined as the videofluoroscopic frame containing the peak of the R-wave on the electrocardiogram and end systole as the frame preceding maximum peak rate fall of the LV pressure $(-\mathrm{dP} / \mathrm{dt})$. Distances between anterior and posterior leaflet edge $\left(\mathrm{d}_{\mathrm{AML} / \mathrm{PML}}\right)$ were computed throughout the cardiac cycle as distances between markers
$\mathrm{A}_{1}$ and $\mathrm{B}_{1}$ (Figure 1, A). Closure Frame 1 was defined as the frame when $\mathrm{d}_{\mathrm{AML} / \mathrm{PML}}$ decreased to a stable minimum value with valve closure immediately after end diastole. Closure Frame 2 was defined as the frame when $d_{\text {AML/PML }}$ just began to increase with valve opening after isovolumic relaxation. Time of mid-systole was defined as ([Closure Frame 2 - Closure Frame 1]/2) + Closure Frame 1 .

\section{Hemodynamics}

Instantaneous LV volume was computed from the epicardial LV markers using a space-filling multiple tetrahedral volume method ${ }^{20}$ (available at: http://circ.ahajournals.org/cgi/content/full/112/9_suppl/ I-423 - R17-M525485). Hemodynamic data were calculated from marker-derived instantaneous LV volumes and analog LV pressures. ${ }^{23}$

\section{Mitral Valve Tenting Area}

Tenting area was computed at mid-systole from sums of marker triangles with the mid point between the saddle horn (number 22, Figure 1, $A$ ) and mid-lateral posterior annular marker (number 18, Figure 1, $A$ ) being the vertex for all triangles (Figure 1,B). Markers 22, $\mathrm{A}_{1}, \mathrm{~A}_{2}, \mathrm{~A}_{3}, \mathrm{~A}_{4}, 18, \mathrm{P}_{1}$, and $\mathrm{P}_{2}$ were the base of the triangles for the total tenting area. To obtain insight into ring effects on tenting area across AML and PML, total tenting area was divided into AML and PML tenting area. Markers 22, $A_{1}, A_{2}, A_{3}$, and $\mathrm{A}_{4}$ were the base of the triangles for AML and $18 ; \mathrm{P}_{1}$ and $\mathrm{P}_{2}$ were the base of the triangles for the PML tenting areas (Figure 1, B). Percent changes in tenting areas were calculated between No_Ring_ISCH and Ring_ISCH as $100 *$ (tenting area Ring_ISCH - tenting area No_Ring_ISCH)/tenting area No_Ring_ISCH and between Ring_BL and Ring_ISCH as $100 *$ (tenting area Ring_ISCH - tenting area No_Ring_BL)/tenting area No_Ring_BL.

\section{Mitral Annular Dimensions}

The S-L mitral annular dimension was calculated as the distance in 3-D space between the saddle horn and mid-lateral posterior annular markers (22 and 18, respectively), and the commissure-commissure (C-C) MA dimension was calculated as the distance between the anterior and posterior commissural annular markers at mid-systole.

\section{Statistical Analysis}

Data are reported as mean \pm 1 standard deviation unless otherwise stated. Continuous data were compared within each group using the 2-tailed Student $t$ test for paired observations with post hoc Bonferroni correction. Ring types were contrasted by comparing absolute changes in the individual states (No_Ring_BL vs No_Ring_ISCH, Ring_BL vs Ring_ISCH, No_Ring_ISCH vs Ring_ISCH) among the 3 groups (PHYSIO, ETL, GEO) using analysis of variance with post hoc HolmSidak correction (Sigmastat 3.5, Systat Software, Inc, San Jose, CA).

\section{RESULTS \\ Hemodynamics}

Table 1 summarizes the hemodynamic changes and mitral annular dimensions measured under baseline conditions (No_Ring_BL, Ring_BL) and during ischemia (No_Ring _ISCH, Ring_ISCH), which were consistent with acute ischemia as reflected by increased LV end-diastolic pressure, decreased maximum $\mathrm{LV}$ pressure, and $\mathrm{dP} / \mathrm{dt}$ absolute values. Heart rate did not change during ischemia. MR grade was significantly greater during ischemia without ring implantation (No_Ring_ISCH) in all groups compared with baseline (No_Ring_BL); furthermore, all 3 rings effectively prevented MR during acute $\mathrm{LV}$ ischemia. 
TABLE 1. Hemodynamic data and mitral annular dimensions

\begin{tabular}{|c|c|c|c|c|c|}
\hline & \multicolumn{4}{|c|}{ Physio (Edwards Lifesciences, Irvine, Calif) } & \multirow{2}{*}{$\frac{\text { IMR ETLogix (Edwards Lifesciences) }}{\text { No_Ring_BL }}$} \\
\hline & No_Ring_BL & No_Ring_ISCH & Ring_BL & Ring_ISCH & \\
\hline MR grade & $0.6 \pm 0.2$ & $1.1 \pm 0.4^{*}$ & $0.2 \pm 0.2$ & $0.4 \pm 0.3$ & $0.3 \pm 0.3$ \\
\hline $\mathrm{HR}\left(\min ^{-1}\right)$ & $93 \pm 13$ & $90 \pm 11$ & $92 \pm 12$ & $90 \pm 14$ & $82 \pm 7$ \\
\hline LVEDV (mL) & $124 \pm 24$ & $133 \pm 34^{*}$ & $124 \pm 26$ & $135 \pm 36 \ddagger$ & $126 \pm 21$ \\
\hline $\mathrm{dP} / \mathrm{dt}_{\max }(\mathrm{mm} \mathrm{Hg} / \mathrm{sec})$ & $1324 \pm 330$ & $1005 \pm 231 *$ & $1365 \pm 332$ & $1077 \pm 225 \ddagger$ & $1177 \pm 387$ \\
\hline $\mathrm{LVP}_{\max }(\mathrm{mm} \mathrm{Hg})$ & $94 \pm 9$ & $71 \pm 7^{*}$ & $94 \pm 6$ & $75 \pm 9 \ddagger$ & $94 \pm 4$ \\
\hline $\mathrm{S}-\mathrm{L}(\mathrm{cm})$ & $2.73 \pm 0.27$ & $2.95 \pm 0.31 *$ & $2.44 \pm 0.16$ & $2.50 \pm 0.16 \ddagger$ & $2.80 \pm 0.21$ \\
\hline $\mathrm{C}-\mathrm{C}(\mathrm{cm})$ & $3.92 \pm 0.23$ & $4.00 \pm 0.28 *$ & $3.31 \pm 0.07$ & $3.30 \pm 0.08 \ddagger$ & $3.87 \pm 0.26$ \\
\hline
\end{tabular}

$M R$, Mitral regurgitation; $H R$, heart rate; $L V E D V$, left ventricular end-diastolic volume; $L V P$, left ventricular pressure; $S$ - $L$, septal-lateral; $C$ - $C$, commissure-commissure; $I S C H$, ischemia. All data are mean \pm 1 standard deviation. $* P<.05$ vs No Ring BL. $\dagger P<.05$ vs Ring BL. $\ddagger P<.05$ vs No Ring ISCH.

\section{Mitral Valve Tenting Areas}

Septal-lateral tenting areas. Without an annuloplasty ring implanted, all tenting areas (total, AML, and PML tenting area) increased significantly during ischemia (No_Ring_BL vs No_Ring_ISCH, all $P<.05$; Figure 2 ).

Ring implantation significantly reduced all tenting areas (total, AML, and PML tenting area) during LV ischemia (No_Ring_ISCH vs Ring_ISCH, all $P<.05$; Figure 3, $A-C)$. Figure $4, A$ shows the relative changes in tenting area in the individual states. During ischemia, the ETL and GEO reduced total and PML tenting area (No_Ring ISCH vs Ring_ISCH: ETL vs PHYSIO, $P<.05$ and GEO vs PHYSIO, $P<.05$; Figure $4, A$ ), but not AML tenting area compared with PHYSIO (No_Ring_ISCH vs Ring_ ISCH: ETL vs PHYSIO, not significant, and GEO vs PHYSIO, not significant; Figure 4, $A$ ). The relative amount of PML tenting area reduction during ischemia was approximately 2 times greater with the ETL and GEO compared with the PHYSIO (No_Ring_ISCH vs Ring_ISCH, $-23.7 \% \pm 10.1 \%$ and $-22.1 \% \pm 7.1 \%$ vs $-11.0 \% \pm$ $7.5 \%$, respectively, both $P<.05$; Figure $4, A$ ).

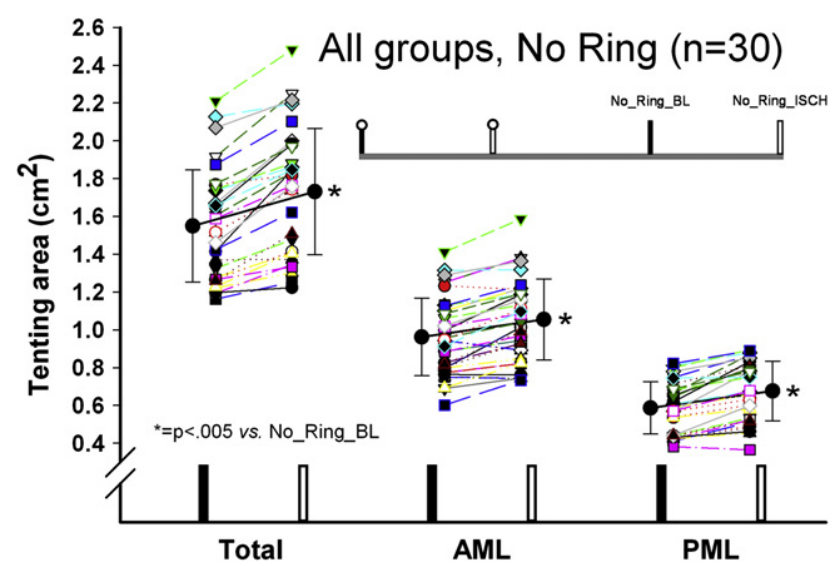

FIGURE 2. Total, AML, and PML, respectively, S-L tenting areas in animals from all 3 groups with no ring implanted under baseline conditions and during acute posterolateral LV ischemia. $A M L$, Anterior mitral leaflet; $B L$, baseline; $I S C H$, ischemia; $P M L$, posterior mitral leaflet.
Figure 3, $D$ to $F$ shows the changes in tenting areas with the respective rings implanted (Ring BL vs Ring ISCH). The induction of ischemia resulted in an increase of PML tenting area in the PHYSIO group (Ring_BL vs Ring_ISCH, $P<.05$; Figure 3, $D$ ) and of total and AML tenting area in the GEO group (Ring_BL vs Ring_ISCH, both $P<.05$; Figure $3, F$ ).

\section{Mitral Annular Dimensions}

Table 1 shows the mitral annular dimensions for all groups. With no ring implanted, mitral annular S-L and $\mathrm{C}-\mathrm{C}$ dimensions increased in all 3 groups during ischemia (No_Ring_BL vs No_Ring_ISCH, all $P<.005$ ). Relative to ischemia without ring, all rings significantly reduced both mitral annular S-L and C-C diameter (No_Ring_ISCH vs Ring_ISCH, all $P<.005)$. Figure $4, B$ shows the relative changes in mitral annular dimensions. The GEO provided the greatest amount of mitral annular S-L reduction, followed by the ETL and PHYSIO (GEO: $-30 \% \pm 4 \%$ vs ETL: $-21 \% \pm 4 \%, P<.05$, and ETL: $-21 \% \pm 4 \%$ vs PHYSIO: $-11 \% \pm 8 \%, P<.05)$. In contrast, the PHYSIO and ETL provided a greater amount of mitral annular C-C reduction than the GEO $(-17 \% \pm 4 \%$ and $-19 \% \pm 3 \%$ vs $-8 \% \pm 5 \%$, respectively, both $P<.05)$. After any of the 3 types of rings were implanted, no relevant changes in mitral annular dimensions during ischemia were observed (Ring_BL vs Ring_ISCH).

\section{DISCUSSION}

The principal findings of this study were as follows: (1) Acute posterolateral LV ischemia increased all tenting areas, that is, total, AML, and PML tenting areas; (2) All 3 ring types reduced ischemia-induced increases in all 3 tenting areas; (3) ETL and GEO reduced total and PML, but not AML tenting area, to a greater extent than the PHYSIO; (4) GEO reduced the mitral annular S-L dimension to a greater extent than the ETL, but the effects of the ETL and GEO on AML and PML tenting areas during ischemia were similar. 
TABLE 1. Continued

\begin{tabular}{|c|c|c|c|c|c|c|}
\hline \multicolumn{3}{|c|}{ IMR ETLogix (Edwards Lifesciences) } & \multicolumn{4}{|c|}{ GeoForm (Edwards Lifesciences) } \\
\hline No_Ring_ISCH & Ring_BL & Ring_ISCH & No_Ring_BL & No_Ring_ISCH & Ring_BL & Ring_ISCH \\
\hline $1.2 \pm 1.2^{*}$ & $0.2 \pm 0.2$ & $0.2 \pm 0.2$ & $0.5 \pm 0.4$ & $1.5 \pm 0.9^{*}$ & $0.2 \pm 0.2$ & $0.2 \pm 0.3$ \\
\hline $82 \pm 6$ & $80 \pm 10$ & $82 \pm 7$ & $91 \pm 10$ & $92 \pm 10$ & $92 \pm 11$ & $93 \pm 10$ \\
\hline $130 \pm 23$ & $126 \pm 21$ & $131 \pm 22 \ddagger$ & $112 \pm 14$ & $122 \pm 17^{*}$ & $110 \pm 13$ & $121 \pm 16 \ddagger$ \\
\hline $921 \pm 294 *$ & $1201 \pm 380$ & $923 \pm 239 \ddagger$ & $1342 \pm 335$ & $1012 \pm 242^{*}$ & $1407 \pm 448$ & $1085 \pm 231 \ddagger$ \\
\hline $72 \pm 9^{*}$ & $96 \pm 4$ & $75 \pm 7 \ddagger$ & $95 \pm 10$ & $74 \pm 7 *$ & $96 \pm 6$ & $76 \pm 6 \ddagger$ \\
\hline $3.00 \pm 0.20 *$ & $2.32 \pm 0.15$ & $2.38 \pm 0.15 \dagger, \ddagger$ & $2.67 \pm 0.21$ & $2.91 \pm 0.21^{*}$ & $1.99 \pm 0.09$ & $2.04 \pm 0.09 \dagger$ \\
\hline $3.96 \pm 0.24 *$ & $3.20 \pm 0.15$ & $3.21 \pm 0.16 \ddagger$ & $3.74 \pm 0.27$ & $3.83 \pm 0.30^{*}$ & $3.50 \pm 0.11$ & $3.51 \pm 0.11 \ddagger$ \\
\hline
\end{tabular}

Effect of Acute Posterolateral Left Ventricular Ischemia on Tenting Areas: No_Ring_BL Versus No_Ring_ISCH

Without the presence of an annuloplasty ring, all measured tenting areas (total, AML, and PML tenting area) increased with acute localized posterolateral LV wall ischemia. Watanabe and colleagues ${ }^{24}$ measured AML and PML tenting heights in 12 patients with chronic IMR using real time 3-D echocardiography and found that maximum tenting occurred in the AML and never in the PML. In contrast, we found that the absolute increases in AML and PML tenting areas with no ring implanted were identical (No_Ring_BL vs No_Ring_ISCH, AML: $+0.09 \pm 0.07 \mathrm{~cm}^{2}$, PML: $+0.09 \pm 0.06 \mathrm{~cm}^{2}$ ). This discordance in findings could be explained by several factors, including the length of ischemia (acute vs chronic), the site of LV wall ischemia (localized posterolateral vs multi-segmental ischemia), the different species, or the differences in imaging modalities used. Regardless of these differences, our data indicate that PML tethering plays an equally important role in the pathophysiology of IMR under these acute experimental conditions. This hypothesis is supported by Magne and colleagues, ${ }^{7}$ who found that the degree of preoperative PML tethering is a predictive factor for recurrent MR in patients with IMR undergoing ring annuloplasty.

\section{Effect of Annuloplasty Ring Implantation on Tenting Areas During Acute Myocardial Ischemia: No_Ring_ISCH Versus Ring_ISCH}

To date, neither clinical nor experimental in vivo studies exist comparing the effects of conventional annuloplasty rings with disease-specific FMR/IMR rings on mitral valve geometry or mitral annular dimensions during myocardial ischemia. While all 3 ring types decreased all tenting areas (and effectively prevented MR) in this in vivo experimental ovine preparation, the amount of mitral annular S-L reduction was not directly proportional to the decrease in tenting areas observed. The relative amount of mitral annular S-L reduction during acute myocardial ischemia after ring implantation (No_Ring_ISCH vs Ring_ISCH; Figure 4, $A$ ) was smallest for the PHYSIO $(15 \% \pm 4 \%)$, greater for the ETL $(21 \% \pm 4 \%)$, and largest for the GEO
$(30 \% \pm 4 \%)$. As expected from these values, the PHYSIO decreased tenting area to the smallest extent (No_Ring_ISCH vs Ring_ISCH; Figure 4, $A$ ). However, to our surprise, the ETL and GEO provided a similar amount of reduction in tenting areas (Figure 4, A). Hypothetically, the GEO's more radical mitral annular S-L downsizing could induce leaflet displacements that may prevent further reduction of tenting areas on an annular level. It is of note that the reductions in tenting area observed in our study were considerably smaller than those reported in clinical studies, in which the approximate decrease in tenting area included $50 \%$ to $60 \%$ after ETL ring implantation ${ }^{5,16}$ and $75 \%$ in tenting volume after GEO implantation. ${ }^{10}$ These observed discrepancies are most probably due to a greater tethering (and, thus, greater tenting areas) of the mitral valve before ring implantation in patients with chronic IMR.

\section{Effect of Ischemia on Tenting Areas With Annuloplasty Rings Inserted: Ring_BL Versus Ring_ISCH}

Another interesting observation was that tenting areas may be affected by regional ischemia despite the presence of an annuloplasty ring (increases in total and AML tenting area with the GEO and in PML tenting area with the PHYSIO; Figure 3, $D$ and $F$ ). These increaes in tenting area are most probably due to ischemia-induced alterations of the subvalvular apparatus and may therefore provide further evidence for the theory that annuloplasty ring implantation alone is not effective in preventing the recurrence of mitral regurgitation due to ongoing $\mathrm{LV}$ dilation.

\section{Clinical Inferences}

As mentioned above, the GEO provided the greatest amount of mitral annular septal-lateral downsizing, but did not reduce tenting areas to a greater extent than ETL. We therefore speculated that such radical mitral annular S-L downsizing could induce leaflet displacements that may prevent further reduction of tenting areas on an annular level. It is conjectured that the addition of a subvalvular adjunctive procedure, for example, as proposed by Kron and colleagues ${ }^{25}$ or Langer and colleagues ${ }^{26}$ may provide additional benefit in terms of tenting area reduction. Furthermore, compared with the PHYSIO ring, the ETL and 

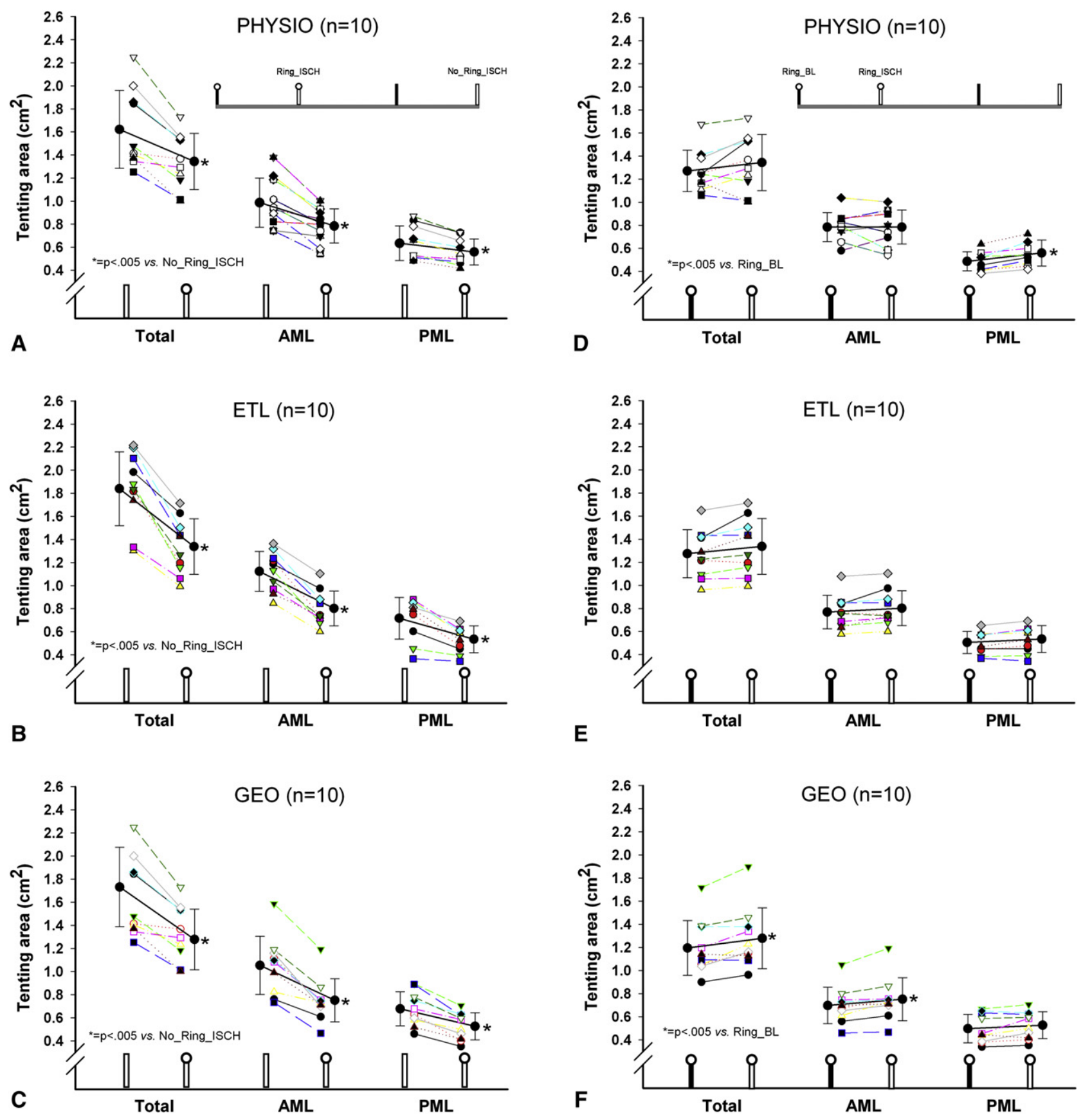

FIGURE 3. Total, AML, and PML, respectively, S-L tenting areas in animals from all 3 groups during acute posterolateral LV ischemia with and without annuloplasty ring (A-C) and with annuloplasty rings implanted under baseline conditions and during ischemia (D-F). $A M L$, Anterior mitral leaflet; $P M L$, posterior mitral leaflet; GEO, GeoForm; PHYSIO, Physio; ETL, IMR ETLogix.

GEO rings were more effective in reducing PML, but not AML, tenting area. These findings indicate that the main effect of annuloplasty rings is to pull the PML toward the AML, which, at least in this acute model, suggests that IMR annuloplasty rings should be designed to target the posterior muscular mitral annular sector instead of the fibrous anterior portion of the mitral annulus.

\section{Limitations}

Caution is certainly necessary in extrapolating these acute experimental findings to patients. First, differences between ovine and human mitral valve anatomy exist. Walmsley ${ }^{27}$ reported that the central zone of the AML is more rigid in sheep hearts than in human hearts. Such rigidity might attenuate alterations in tenting area compared 


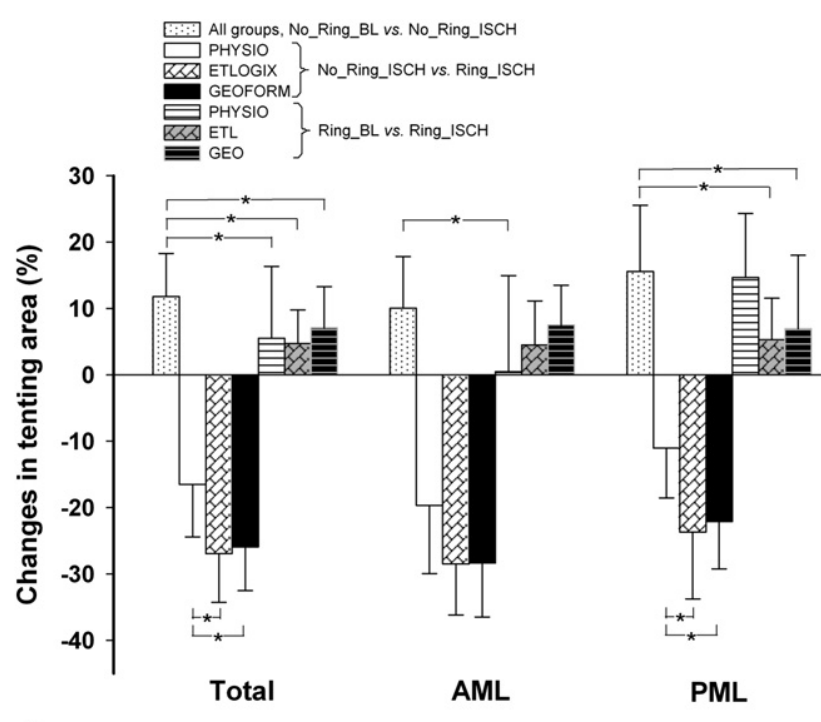

A

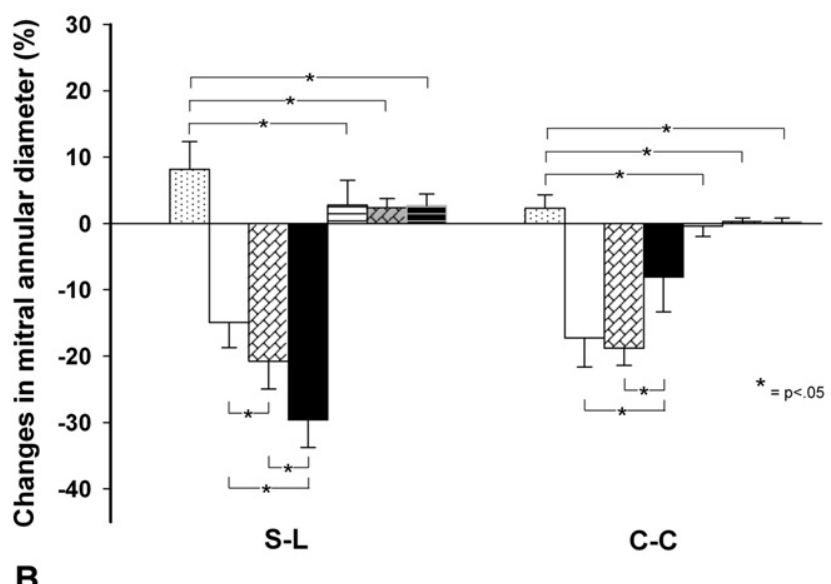

FIGURE 4. Relative changes in tenting area (A) and mitral annular diameters (B) among the respective experimental conditions (see "Materials and Methods" for details). $A M L$, Anterior mitral leaflet; $P M L$, posterior mitral leaflet; $C$ - $C$, commissure-commissure; $S$ - $L$, septal-lateral; $B L$, baseline; $I S C H$, ischemia.

with patients, although we assume it is a minor contributor because ovine leaflets are nonetheless flexible. Furthermore, from our own experience, the position of the papillary muscles relative to the leaflets may be slightly different in sheep versus humans, and thus could impair the extrapolation of our findings to patients. Second, the pathologic perturbations of this acute ischemic experimental preparation undoubtedly differ from those in patients with chronic FMR/IMR, even though previous studies from our laboratory have shown that papillary muscle displacement differs only slightly between acute and chronic ovine ischemic models. For example, in an ovine model of acute IMR, Lai and colleagues ${ }^{28}$ found anteroapical and posterobasal displacement of the anterior and posterior papillary muscle tips, respectively, whereas Tibayan and colleagues ${ }^{29}$ induced chronic IMR in sheep and noted posterolateral and posterolateral plus basal displacement of the anterior and posterior papillary muscle tips, respectively. These differences in 3-D papillary muscle behavior between acute and chronic ischemia presumably affect 3-D leaflet geometry. Ryan and colleagues ${ }^{9}$ found that the tenting sites with ischemic MR were most prominent between the 2 commissures during acute IMR, but more pronounced toward the anterior commissure during chronic IMR. Future studies in a chronic experimental setting or in patients with chronic IMR that focus on the effects of rings are needed. A third limitation is that downsized ring annuloplasty is the procedure of choice when using PHYSIO rings in patients with IMR/ FMR, ${ }^{3,30,31}$ but in our study, disease-specific IMR ETL and GEO rings were compared with true-sized PHYSIO rings. The benefit of disease-specific ring designs compared with a downsized PHYSIO ring can therefore not be assessed, and no recommendation can be made with respect to the use of a PHYSIO ring for the treatment of IMR Fourth, our experimental approach tracks distinct anatomic landmarks in all 3 dimensions and, thus, includes displacements of the respective structures in any direction in 3-D space. Consequently, our results may differ from tenting area measurements obtained from clinical imaging techniques where only one 2-dimensional longitudinal crosssectional view is obtained. Last, the quantification of tenting areas and the separation into AML and PML tenting area after valve repair using current clinical imaging modalities may be difficult because of artifacts resulting from ring implantation.

\section{CONCLUSIONS}

Disease-specific FMR/IMR rings (ETL, GEO) reduce total tenting area to a greater extent in response to acute LV ischemia than true-sized PHYSIO rings, predominantly via reducing PML tenting area. However, despite its radical 3-D shape and greater amount of mitral annular S-L downsizing, the GEO ring did not reduce tenting areas more than the ETL ring, suggesting that radical S-L downsizing could induce leaflet displacements that may prevent a further reduction of tenting areas on an annular level. Clinical studies are needed to determine whether these findings translate to patients.

The authors thank Paul Chang, Maggie Brophy, George T. Daughters III, Sigurd Hartnett, Saideh Fahramand, Lauren R. Davis, Eleazar Briones, and Kathy Vo for expert technical assistance.

\section{References}

1. Kwan J, Shiota T, Agler DA, Popovic ZB, Qin JX, Gillinov MA, et al. Geometric differences of the mitral apparatus between ischemic and dilated cardiomyopathy with significant mitral regurgitation: real-time three-dimensional echocardiography study. Circulation. 2003;107:1135-40. 
2. Gelsomino S, Lorusso R, De Cicco G, Capecchi I, Rostagno C, Caciolli S, et al. Five-year echocardiographic results of combined undersized mitral ring annuloplasty and coronary artery bypass grafting for chronic ischaemic mitral regurgitation. Eur Heart J. 2008;29:231-40.

3. Braun J, van de Veire NR, Klautz RJ, Versteegh MI, Holman ER, Westenberg JJ, et al. Restrictive mitral annuloplasty cures ischemic mitral regurgitation and heart failure. Ann Thorac Surg. 2008;85:430-7.

4. Watanabe N, Ogasawara Y, Yamaura Y, Yamamoto K, Wada N, Kawamoto T, et al. Geometric differences of the mitral valve tenting between anterior and inferior myocardial infarction with significant ischemic mitral regurgitation: quantitation by novel software system with transthoracic real-time three-dimensional echocardiography. J Am Soc Echocardiogr. 2006;19:71-5.

5. Daimon M, Fukuda S, Adams DH, McCarthy PM, Gillinov AM, Carpentier A, et al. Mitral valve repair with Carpentier-McCarthy-Adams IMR ETlogix annuloplasty ring for ischemic mitral regurgitation: early echocardiographic results from a multi-center study. Circulation. 2006;114:I588-93.

6. Song JM, Qin JX, Kongsaerepong V, Shiota M, Agler DA, Smedira NG, et al. Determinants of ischemic mitral regurgitation in patients with chronic anterior wall myocardial infarction: a real time three-dimensional echocardiography study. Echocardiography. 2006;23:650-7.

7. Magne J, Pibarot P, Dagenais F, Hachicha Z, Dumesnil JG, Senechal M. Preoperative posterior leaflet angle accurately predicts outcome after restrictive mitral valve annuloplasty for ischemic mitral regurgitation. Circulation. 2007;115: 782-91.

8. Bothe W, Nguyen TC, Ennis DB, Itoh A, Carlhall CJ, Lai DT, et al. Effects of acute ischemic mitral regurgitation on three-dimensional mitral leaflet edge geometry. Eur J Cardiothorac Surg. 2008;33:191-7.

9. Ryan L, Jackson B, Parish L, Sakamoto H, Plappert T, Sutton MS, et al. Quantification and localization of mitral valve tenting in ischemic mitral regurgitation using real-time three-dimensional echocardiography. Eur J Cardiothorac Surg. 2007;31:839-44.

10. Armen TA, Vandse R, Crestanello JA, Raman SV, Bickle KM, Nathan NS. Mechanisms of valve competency after mitral valve annuloplasty for ischaemic mitral regurgitation using the GeoForm ring: insights from three-dimensional echocardiography. Eur J Echocardiogr. 2009;10:74-81.

11. Lee AP, Acker M, Kubo SH, Bolling SF, Park SW, Bruce CJ, et al. Mechanisms of recurrent functional mitral regurgitation after mitral valve repair in nonischemic dilated cardiomyopathy: importance of distal anterior leaflet tethering. Circulation. 2009;119:2606-14.

12. Pocar M, Passolunghi D, Moneta A, Di Mauro A, Bregasi A, Mattioli R, et al. Baseline left ventricular function and surgical annular stiffening to predict outcome and reverse left ventricular remodeling after undersized annuloplasty for intermediate-degree ischemic mitral regurgitation. $J$ Thorac Cardiovasc Surg. 2010;139:1529-38. Epub 2009 Dec 6.

13. Matsunaga A, Tahta SA, Duran CM. Failure of reduction annuloplasty for functional ischemic mitral regurgitation. J Heart Valve Dis. 2004;13:390-8.

14. Bothe W, Swanson JC, Ingels NB, Miller DC. How much septal-lateral mitral annular reduction do you get with new ischemic/functional mitral regurgitation annuloplasty rings? J Thorac Cardiovasc Surg. 2010;140:117-21, 121.e1-3. Epub 2010 Jan 13.

15. Bothe W, Kvitting JP, Swanson JC, Hartnett S, Ingels NB, Miller DC. Effects of different annuloplasty rings on anterior mitral leaflet dimensions. J Thorac Cardiovasc Surg. 2010;139:1114-22.

16. Filsoufi F, Castillo JG, Rahmanian PB, Carpentier A, Adams DH. Remodeling annuloplasty using a prosthetic ring designed for correcting type-IIIb ischemic mitral regurgitation. Rev Esp Cardiol. 2007;60:1151-8.

17. Armen TA, Vandse R, Crestanello JA, Raman SV, Bickle KM, Nathan NS. Mechanisms of valve competency after mitral valve annuloplasty for ischaemic mitral regurgitation using the Geoform ring: insights from three-dimensional echocardiography. Eur J Echocardiogr. 2009;10:74-81. Epub 2008 May 13.

18. Timek TA, Dagum P, Lai DT, Liang D, Daughters GT, Tibayan F, et al. Tachycardia-induced cardiomyopathy in the ovine heart: mitral annular dynamic threedimensional geometry. J Thorac Cardiovasc Surg. 2003;125:315-24.

19. Bothe W, Chang PA, Swanson JC, Itoh A, Arata K, Ingels NB, et al. Releasable annuloplasty ring insertion-a novel experimental implantation model. Eur J Cardiothorac Surg. 2009;36:830-2.

20. Niczyporuk MA, Miller DC. Automatic tracking and digitization of multiple radiopaque myocardial markers. Comput Biomed Res. 1991;24:129-42.

21. Daughters G, Sanders W, Miller D, Schwarzkopf A, Mead C, Ingels N. A comparison of two analytical systems for 3-D reconstruction from biplane videoradiograms. Comput Cardiol. 1989;15:79-82.
22. Helmcke F, Nanda NC, Hsiung MC, Soto B, Adey CK, Goyal RG, et al. Color Doppler assessment of mitral regurgitation with orthogonal planes. Circulation. 1987;75:175-83.

23. Glasson JR, Komeda M, Daughters GT 2nd, Bolger AF, Ingels NB Jr, Miller DC. Loss of three-dimensional canine mitral annular systolic contraction with reduced left ventricular volumes. Circulation. 1996;94:II152-8.

24. Watanabe N, Ogasawara Y, Yamaura Y, Kawamoto T, Toyota E, Akasaka T, et al. Quantitation of mitral valve tenting in ischemic mitral regurgitation by transthoracic real-time three-dimensional echocardiography. J Am Coll Cardiol. 2005;45: 763-9.

25. Kron IL, Green GR, Cope JT. Surgical relocation of the posterior papillary muscle in chronic ischemic mitral regurgitation. Ann Thorac Surg. 2002;74:600-1.

26. Langer F, Kunihara T, Hell K, Schramm R, Schmidt KI, Aicher D, et al. RING+ STRING: Successful repair technique for ischemic mitral regurgitation with severe leaflet tethering. Circulation. 2009;120:S85-91.

27. Walmsley R. Anatomy of human mitral valve in adult cadaver and comparative anatomy of the valve. Br Heart J. 1978;40:351-66.

28. Lai DT, Timek TA, Tibayan FA, Green GR, Daughters GT, Liang D, et al. The effects of mitral annuloplasty rings on mitral valve complex 3-D geometry during acute left ventricular ischemia. Eur J Cardiothorac Surg. 2002;22:808-16.

29. Tibayan FA, Rodriguez F, Zasio MK, Bailey L, Liang D, Daughters GT, et al. Geometric distortions of the mitral valvular-ventricular complex in chronic ischemic mitral regurgitation. Circulation. 2003;108(Suppl 1):II116-21.

30. Spoor MT, Geltz A, Bolling SF. Flexible versus nonflexible mitral valve rings for congestive heart failure: differential durability of repair. Circulation. 2006;114: I67-71.

31. Williams ML, Daneshmand MA, Jollis JG, Horton JR, Shaw LK, Swaminathan M, et al. Mitral gradients and frequency of recurrence of mitral regurgitation after ring annuloplasty for ischemic mitral regurgitation. Ann Thorac Surg. 2009;88:1197-201.

\section{Discussion}

Dr Y. Joseph Woo (Philadelphia, Pa). I congratulate you on some fantastic large animal work and a creative model. My question relates to your choice of a single S-L line and 3 points along that line for evaluating the unique plane for your tenting area. That is valid in a planar ring, but in a radically nonplanar surface, the point you have chosen is sort of a high point in the GeoForm ring and therefore does not represent the geometry of the tenting area to the left and right of the posterior midpoint. Would it be markedly different if you integrated across, say, 3 vertical lines, maybe one through the middle and then one perhaps $1 \mathrm{~cm}$ to the right and $1 \mathrm{~cm}$ to the left?

Dr Bothe. You are absolutely right that annuloplasty rings, especially the IMR ETLogix, which is asymmetrically designed, could affect tenting areas in different regions differently. However, our analyses depend on our marker placement. Because we did not place markers on the posterior leaflet in the meridians you mentioned, we cannot determine such changes at this point. It would include an interesting future analysis.

Dr Eugene Grossi (New York, NY). A wonderful experiment. Just a question on your experimental design. Why did you choose a true-size Physio ring? All clinical expertise and use of this ring is in downsizing, and if that is the case, you could think that there are no differences if you just use a ring that gives you a fair amount of S-L shortening to make the subject more ischemia-resistant.

Dr Bothe. It would be desirable to have an additional animal group that received downsized Physio rings. In this experiment we chose to use rings that had similar nominal sizes because that allowed us to get an impression about the magnitude of changes of disease-specific rings compared with the Physio ring. For 
now, we can just speculate that the ring would have similar effects of a downsized Physio and would be similar to an IMR ETLogix or a GeoForm.

Dr Rakesh Suri (Rochester, Minn). Can you share any information regarding the echocardiographic findings? Did the differences in mitral tenting correspond to persistence of MR? What is your hypothesis regarding the effectiveness of ring-induced annular reshaping in preventing recurrence of MR in the setting of chronic ischemia where we know there is progressive and ongoing remodeling of the ventricle?

Dr Bothe. To answer your first question regarding the MR grades, all MR grades increased without a ring implanted, meaning from baseline to ischemia with no ring inserted, all animals developed MR and the MR grades were significantly higher. All rings (Physio, IMR ETLogix, and GeoForm) eliminated the occurrence of acute MR style.

Dr Suri. All rings?

Dr Bothe. Yes, all rings. As for the chronic setting, I agree with you that chronic IMR may affect leaflet geometry differently; for example, this has been shown by Gorman and colleagues in a chronic experimental setting [Gorman JH III, Gorman RC, Jackson BM, Enomoto Y, St John-Sutton MG, Edmunds LH Jr. Annuloplasty ring selection for chronic ischemic mitral regurgitation: lessons from the ovine model. Ann Thorac Surg. 2003;76:155663]. To get an impression about the effects of acute ischemia on papillary muscle geometry in our acute experimental setup, we looked at ventricular changes and papillary muscle displacement. The papillary muscles displaced by approximately $7 \mathrm{~mm}$ in the posterolateral direction, which is close to a chronic scenario, but not identical. So although we would expect changes in the chronic scenario to be similar, it could well be that they are slightly different.

Dr John Ikonomidis (Charleston, SC). In the setting of this acute regional ischemic model, what are the physical determinants of mitral leaflet tenting? Why does it occur? What are the things at play?

Dr Bothe. Pretty much all components of the mitral valve complex can be involved in the pathophysiology of IMR. However, the major physical determinants in our acute model included mitral annular dilatation, LV dilatation, and a displacement of the papillary muscles, mainly the posteromedial papillary muscle.

Dr Ikonomidis. So what you are measuring is actually area under a flat plane on the annulus, and we need to quantify mitral leaflet tenting.

Dr Bothe. Yes.

Dr Ikonomidis. How are you modifying that area with these rings? Are you just bringing the leaflets closer together?

Dr Bothe. That is a good question, because the tenting area is basically a function of mitral annular dimension and the leaflet surface. We know that the GeoForm decreases the mitral annular S-L dimension to a greater extent than the IMR ETLogix. However, our data suggest that radical S-L downsizing could induce leaflet displacements and increased leaflet tethering that, in turn, may prevent a further reduction in tenting area.

Dr Ikonomidis. So does reduction in the S-L dimension directly result in modification of papillary muscle displacement?

Dr Bothe. It could enhance leaflet tethering, but it does not necessarily affect the position of the papillary muscle. We will look at rings effects on the papillary muscles in a future analysis.

Dr Ikonomidis. My point being that it sounds as though with these rings you are not modifying the direct primary cause of....

Dr Bothe. That is correct.

Dr Ikonomidis. And that raises the question of durability of these repairs despite functional improvement acutely.

Dr Bothe. Yes, I think our data even provide certain evidence that it may not be sufficient to treat IMR solely on an annular level. 